\title{
Controle de Fusarium verticillioides em sementes de milho com o óleo essencial de gengibre
}

\author{
Maria Luiza Nunes Costa@ ', Dayanne da Silva Fontela Gonçalves@ ${ }^{1}$, José da Cruz Machado® ${ }^{2}$
}

\author{
${ }^{1}$ Campus de Chapadão do Sul, Universidade Federal do Mato Grosso do Sul, CP 112, CEP 79560-000, Chapadão do Sul, MS, Brasil. \\ ${ }^{2}$ Departamento de Fitopatologia, Universidade Federal de Lavras, CP 3037 , CEP 37200-900, Lavras, MG, Brasil. \\ Corresponding author: Maria Luiza Nunes Costa (luiza.costa@ymail.com) \\ Data de chegada: 10/02/2020. Aceito para publicação em: 07/04/2020.
}

$10.1590 / 0100-5405 / 233888$

\section{RESUMO}

Costa, M.L.N.; Gonçalves, D.S.F.; Machado, J.C. Controle de Fusarium verticillioides em sementes de milho com o óleo essencial de gengibre. Summa Phytopathologica, v.46, n.3, p.250-254, 2020.

O comportamento de isolados da espécie de Fusarium verticillioides presentes nas diferentes microrregiões produtoras de milho, bem como o comportamento dos híbridos utilizados nessas regiões na presença do referido patógeno, seja em sementes, colmos das plantas ou restos de cultura, necessita ser avaliado, visando o melhor manejo das doenças por eles causadas. Com reduzida quantidade de produtos prejudiciais à saúde, tem-se utilizado métodos alternativos, no controle de doenças, reduzindo o uso de agrotóxico e contribuindo para uma agricultura mais sustentável. O objetivo deste trabalho foi avaliar o controle de $F$. verticillioides em sementes de milho utilizando óleo essencial (OE) de gengibre, bem como a sua presença no colmo de plantas originadas a partir dessas sementes. As sementes, naturalmente infestadas, foram tratadas com o óleo essencial de gengibre em seis concentrações $(0,1,2,3,4$ e 5 \%). Foram avaliadas a germinação padrão, sanidade das sementes, emergência e índice de velocidade de emergência em substrato, e presença dos patógenos em plântulas. $\mathrm{O}$ delineamento experimental foi o inteiramente casualizado para os testes de germinação e sanidade, e blocos casualizados para os testes de emergência e incidência da doença em hastes de plântulas de milho. $\mathrm{O}$ OE de gengibre, nas concentrações 0 (zero), 1, 2, 3, 4 e 5 \%, não afetou a germinação das sementes de milho do hibrido avaliado e nas doses de 1, 4 e 5\% proporcionou menor porcentagem de incidência de Fusarium verticillioides. A oscilação na porcentagem de germinação das sementes tratadas com diferentes concentrações do OE de gengibre foi inversamente proporcional à presença do fungo $F$. verticillioides nas sementes. $\mathrm{O}$ índice de velocidade de emergência das sementes tratadas nas diferentes concentrações do $\mathrm{OE}$ de gengibre foi superior na maior concentração. $\mathrm{O} \mathrm{OE}$ de gengibre pode ser utilizado no tratamento de sementes de milho para o controle de $F$. verticillioides nas doses avaliadas.

Palavras-chave: Tratamento de sementes, Inóculo primário, Fungos fitopatógênicos.

\section{ABSTRACT}

Costa, M.L.N.; Gonçalves, D.S.F.; Machado, J.C. Control of Fusarium verticillioides in corn seeds with ginger essential oil. Summa Phytopathologica, v.46, n.3, p.250-254, 2020.

The behavior of isolates of the species Fusarium verticillioides present in different corn-producing microregions, as well as the behavior of hybrids used in these regions in the presence of the above-mentioned pathogen whether in seeds, plant stems or crop remains, needs to be evaluated with the aim of better managing the diseases they cause. Alternative methods with a smaller quantity of products harmful to the health have been employed to control diseases, reducing the use of pesticides and contributing to more sustainable agriculture. The objective of this study was to evaluate the control of $F$. verticillioides in corn seeds with essential oil (EO) of ginger, as well as the presence of this pathogen in the stem of plants originated from these seeds. Naturally infested seeds were treated with ginger essential oil at six concentrations $(0,1 \%, 2 \%, 3 \%, 4 \%$ and $5 \%)$. Evaluation included standard germination, seed health, emergence and emergence speed index in the substrate, and presence of pathogens in the seedlings. Experimental design was completely randomized for germination and health tests and in randomized blocks for the tests of emergence and disease incidence in the stems of corn seedlings. Ginger EO, at the concentrations 0 (zero), $1 \%, 2 \%, 3 \%, 4 \%$ and $5 \%$, did not affect corn seed germination considering the evaluated hybrid and provided lower $F$. verticillioides incidence percentage at $1 \%, 4 \%$ and $5 \%$. The oscillation in the germination percentage of seeds treated with different concentrations of ginger EO was inversely proportional to the presence of the fungus $F$. verticillioides in the seeds. The emergence speed index of seeds treated with different concentrations of ginger EO was superior at the highest concentration. Ginger EO can be used in the treatment of corn seeds to control $F$. verticillioides at the evaluated concentrations.

Keywords: Seed treatment, primary inoculum, phytopathogenic fungi.

No Brasil, a produção de grãos de milho safrinha ocupa uma área de 11.033,9 milhões de hectares, com uma produção de 58.591,9 milhões de toneladas. No Estado de Mato Grosso do Sul, a área cultivada é de 1.700 milhões de hectares, tendo uma produtividade de $5.138 \mathrm{Kg} \mathrm{ha}^{-1}$ e produção de 8.734,6 milhões de toneladas (19).

Sementes de milho contaminadas com fungos como o Fusarium verticillioides e F. graminearum $(6,11,25)$, Stenocarpella macrospora e $S$. maydis (5) poderão causar danos na planta adulta como podridões 
de colmo e na própria semente, afetando a emergência das mesmas e consequentemente a produção. A transmissão de patógenos através das sementes pode ocorrer pela presença de esporos, estruturas de sobrevivência, ou resíduos de colheita contendo inóculo junto à semente $(18,20)$ e originar focos primários de doenças $(14)$.

A presença de patógenos nas sementes no plantio garante o aumento de inóculo em área de cultivos sucessivos, a redução do poder germinativo e vigor da semente, a redução da produtividade, além de servir como meio de perpetuação de doenças de geração a geração e aumento de custos de produção para controle das doenças $(14,20)$. Do ponto de vista sanitário, a semente ideal seria aquela livre de microorganismo indesejável. Porém isso nem sempre é possível, uma vez que a qualidade das sementes é altamente influenciada pelas condições climáticas sob as quais são produzidas e armazenadas (10).

Dentre algumas formas de controle preventivo de doenças, o manejo de sementes que envolvem o tratamento químico por fungicidas, no caso de fungos, ao lado de tecnologias de beneficiamento e armazenamento em condições controladas tem sido a medida mais praticada em todo o mundo, pela sua simplicidade, baixo custo e outras vantagens de natureza ecológica (13).

Métodos alternativos de controle de doenças de plantas são importantes no manejo de doenças de plantas buscando diminuir o uso dos agrotóxicos e contribuir para uma agricultura mais adequada às novas exigências de qualidade ambiental e de obtenção de novas moléculas químicas no controle de patógenos $(26,21)$ Esses métodos alternativos eliminam os riscos de contaminação ambiental, causam menor impacto na biodiversidade e geram menores desequilíbrios biológicos (2). Estudos têm demonstrado que óleos essenciais de algumas espécies vegetais são eficientes no controle de doenças de plantas, seja pela ação fungitóxica direta ou pela indução de resistência às doenças da cultura tratada. Como exemplos tem-se o OE de Syzygium aromaticum na concentração de $0,15 \%$ que controlou os fungos Rhizoctonia solani, Fusarium solani, Fusarium oxysporum (8). O OE de Melaleuca alternifolia inibiu o desenvolvimento de Macrophomina phaseolina, Alternaria alternata e Sclerotinia sclerotiorum a partir das concentrações $0,2 \%$ (17). Sementes de soja com o fungo Colletotrichum truncatum foram tratadas com os óleos Hyptis marrubioides, Aloysia gratissima e Cordia verbenacea sendo eficiente na concentração de $1 \%$, resultado comparável ao tratamento de sementes com o fungicida carbendazim. Os óleos foram eficientes em reduzir a germinação dos conídios, o crescimento micelial e a reprodução do fungo, mas permanecendo viável (16). Nesse sentido este trabalho objetivou avaliar o controle do fungo $F$. verticillioides presente naturalmente em sementes do híbrido de milho BX 970 YG tratadas com OE de gengibre, e sua taxa de transmissão no colmo de plântulas originadas das sementes tratadas.

\section{MATERIAL E MÉTODOS}

Utilizou-se sementes do híbrido BX 970 YG, naturalmente infestadas com o fungo $F$. verticillioides. Os testes de germinação e de sanidade (blotter test) foram realizados para verificação da qualidade fisiológica e sanitária. Os patógenos presentes foram identificados baseando-se em literatura pertinente $(1,4)$ utilizando-se microscópio estereoscópico e ótico, quando necessário, e isolados em meio de cultura para armazenamento.

O teste foi conduzido com 4 repetições de 50 sementes, perfazendo um total de 200 sementes por tratamento. Utilizou-se a metodologia do Rolo de Papel, onde o substrato foi umedecido com água na proporção
2,5 vezes o peso do papel. A temperatura utilizada foi de $25^{\circ} \mathrm{C}$, em ambiente controlado, e a avaliação realizada aos 4 e 7 dias, seguindo os critérios estabelecidos nas Regras para Análise de Sementes (RAS) do Ministério da Agricultura Pecuária e Abastecimento (3).

$O$ teste de sanidade foi realizado utilizando-se 200 sementes, distribuídas em caixas tipo gerbox $12 \times 12 \times 3,5 \mathrm{~cm}, 25$ sementes/ gerbox, contendo 2 folhas de papel mata-borrão esterilizados e umedecidos com ágar-água 1\% (10 g de ágar/1.000 mL de água) (12), utilizando a técnica de congelamento. Os gerboxes com as sementes foram mantidas em câmara tipo BOD, sob fotoperíodo de $12 \mathrm{~h}$, a uma temperatura de $22^{\circ} \mathrm{C}$, sob luz branca, por 24 horas, em seguida foram levadas para congelador $\left(-20^{\circ} \mathrm{C}\right)$ por 24 horas, e finalmente retornadas à incubadora a $22^{\circ} \mathrm{C}$, por mais 5 dias. Ao final foi registrada a ocorrência de cada espécie fúngica, em cada semente, com base em descrições existentes para esse tipo de análise $(1,4)$.

Os resultados obtidos foram expressos em porcentagem de sementes infectadas e/ou contaminadas, fornecendo a incidência de cada fungo patogênico nas sementes.

As sementes foram tratadas com o $\mathrm{OE}$ de gengibre obtido do Departamento de Química, da Universidade Federal de Lavras (DQI/ UFLA), em seis concentrações ( $0,1,2,3,4$ e 5 \%). O Óleo essencial foi diluído em água, nas devidas concentrações e adicionados diretamente às porções de sementes $(0,3 \mathrm{~kg}$ por tratamento), previamente umedecidas com água na proporção de $1 \mathrm{~L} 100 \mathrm{~kg}^{-1}$ de sementes, no interior de sacos plásticos, procedendo-se em seguida a homogeneização.

As avaliações das sementes tratadas constaram do blotter test, conforme descrito anteriormente, avaliação físiológica através do teste padrão de germinação das sementes, como descrito acima, testes de emergência de plântulas, índice de velocidade de emergência, além da transmissibilidade de patógenos das sementes às plântulas. Os três últimos testes foram realizados em uma metodologia única utilizando mistura de solo, areia e composto orgânico, esterilizados, dispostos em bandejas, constando de quatro repetições de 50 sementes por tratamento. A irrigação foi realizada diariamente, utilizando-se mangueira acoplada a um bico pulverizador.

O índice de velocidade de emergência (IVE) foi avaliado por meio de contagens diárias de estande até a estabilização do mesmo. Os valores do referido índice foram determinados empregando-se a fórmula de Maguire (16):

$$
I V E=\frac{E_{1}}{N_{1}}+\frac{E_{2}}{N_{2}}+\ldots+\frac{E_{n}}{N_{n}}
$$

onde:

$\mathrm{N} 1 \ldots \ldots . \mathrm{n}=\mathrm{N}^{\mathrm{O}}$ de dias decorridos da semeadura até a respectiva contagem.

$\mathrm{E} 1$.......En $=\mathrm{N}^{\mathrm{O}}$ de plântulas emergidas em cada dia considerado.

A transmissibilidade de fungos para as plântulas foi realizada ao final do teste de IVE, aos 30 dias após a emergência. Amostras das plântulas foram removidas e analisadas quanto à presença de $F$. verticillioides através do plaqueamento de partes do coleóptilo em meio de cultura Batata-Dextrose-Ágar (BDA), de acordo com Teixeira e Machado (27).

A taxa de infecção das sementes dos fungos é a relação entre os coleóptilos infectados pelo fungo e o total de coleóptilos, foram calculadas de acordo com Teixeira e Machado (27) e Rey et al; (22).

O delineamento experimental utilizado foi inteiramente casualizado nos testes de germinação e sanidade e em blocos casualizados nos testes de emergência, IVE e incidência de $F$. verticillioides nas plântulas. 
As análises estatísticas, ANAVA e regressão, foram realizadas utilizando-se o programa $\operatorname{SISVAR}^{\circledR}(8)$.

\section{RESULTADOS E DISCUSSÃO}

O OE de gengibre nas doses de 1, 4 e $5 \%$ proporcionaram menores porcentagens de incidência de $F$. verticillioides, nas sementes de milho do hibrido avaliado, não afetando a germinação das sementes nas concentrações avaliadas ( 0 (zero), 1, 2, 3, 4 e 5 \%).

As porcentagens de germinação na primeira contagem foram influenciadas pelas diferentes concentrações do óleo de gengibre, sendo que as sementes tratadas com as concentrações de 2 e $3 \%$ apresentaram germinação inferior aos demais tratamentos (Figura 1). No entanto, foi observado que na contagem final, o uso das doses do OE de gengibre no tratamento das sementes não influenciou a germinação (Figura 1). As sementes foram capazes de superar qualquer efeito supressor da germinação presente no $\mathrm{OE}$ de gengibre.

A avaliação da sanidade das sementes de milho tratadas com o $\mathrm{OE}$ de gengibre resultaram em diferenças na incidência dos fungos $F$. verticillioides, Aspergillus flavus e Penicillium sp. avaliados no teste $(\mathrm{P}>5 \%)$ (Figura 2).

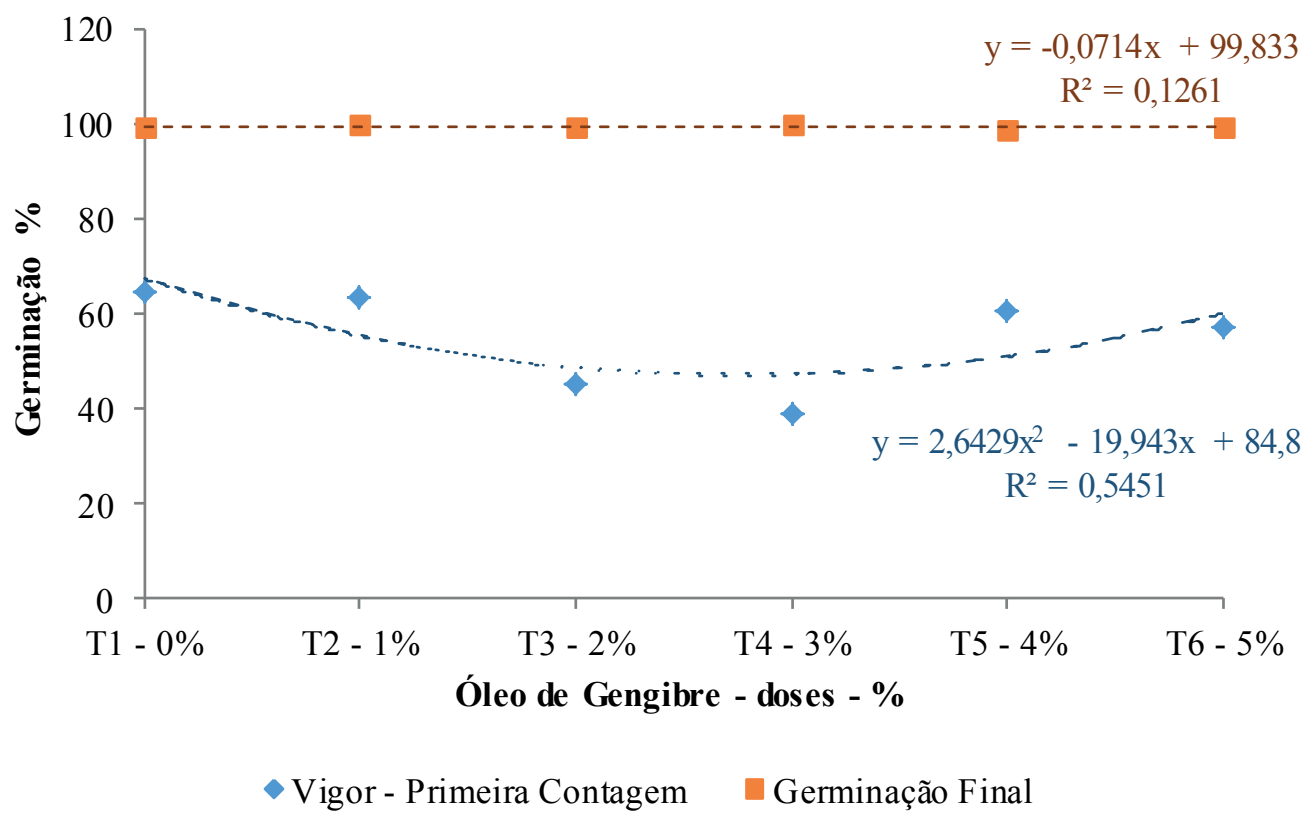

Figura 1. Contagem inicial e total da germinação as sementes de milho tratadas com óleo essencial de gengibre em diferentes concentrações (\%). UFMS - Chapadão do Sul/MS. 2016.

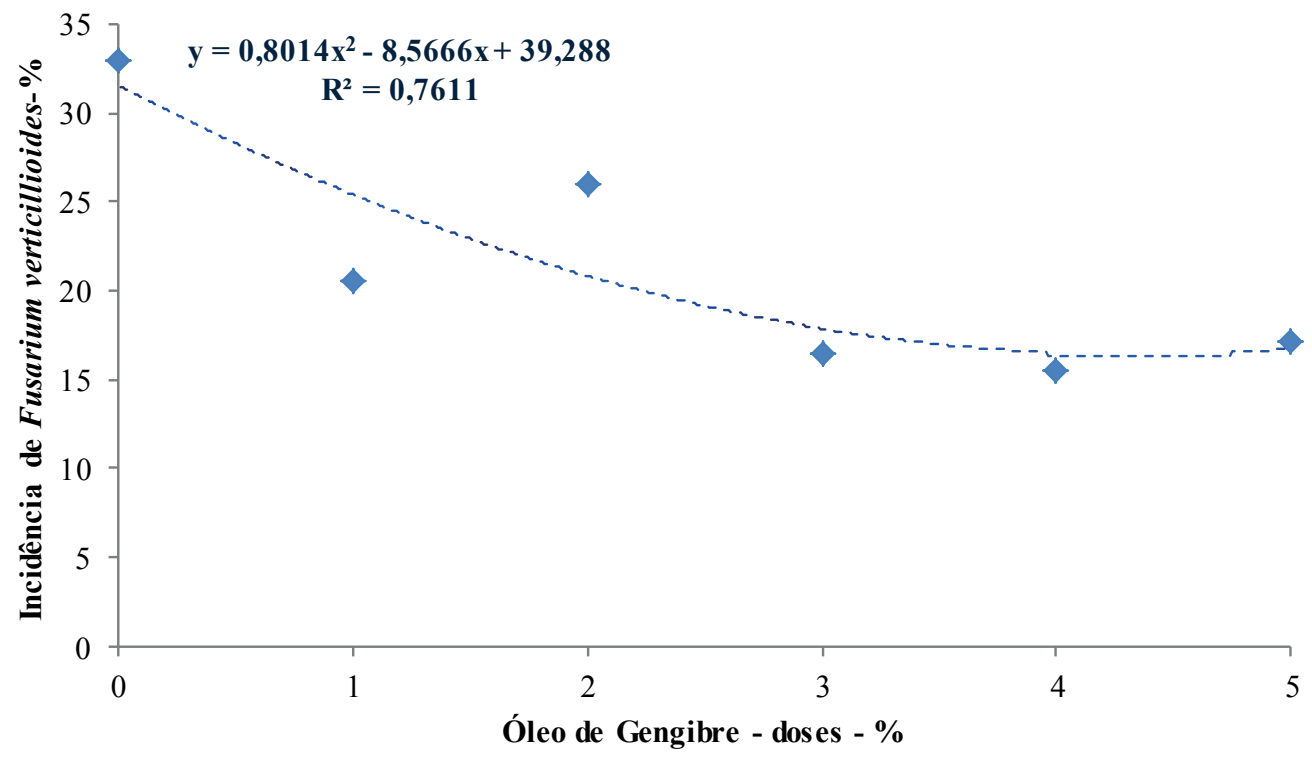

Figura 2. Incidência de fungos em sementes de milho tratadas com óleo essencial de gengibre em diferentes concentrações (\%). UFMS - Chapadão do Sul/MS. 2016. 


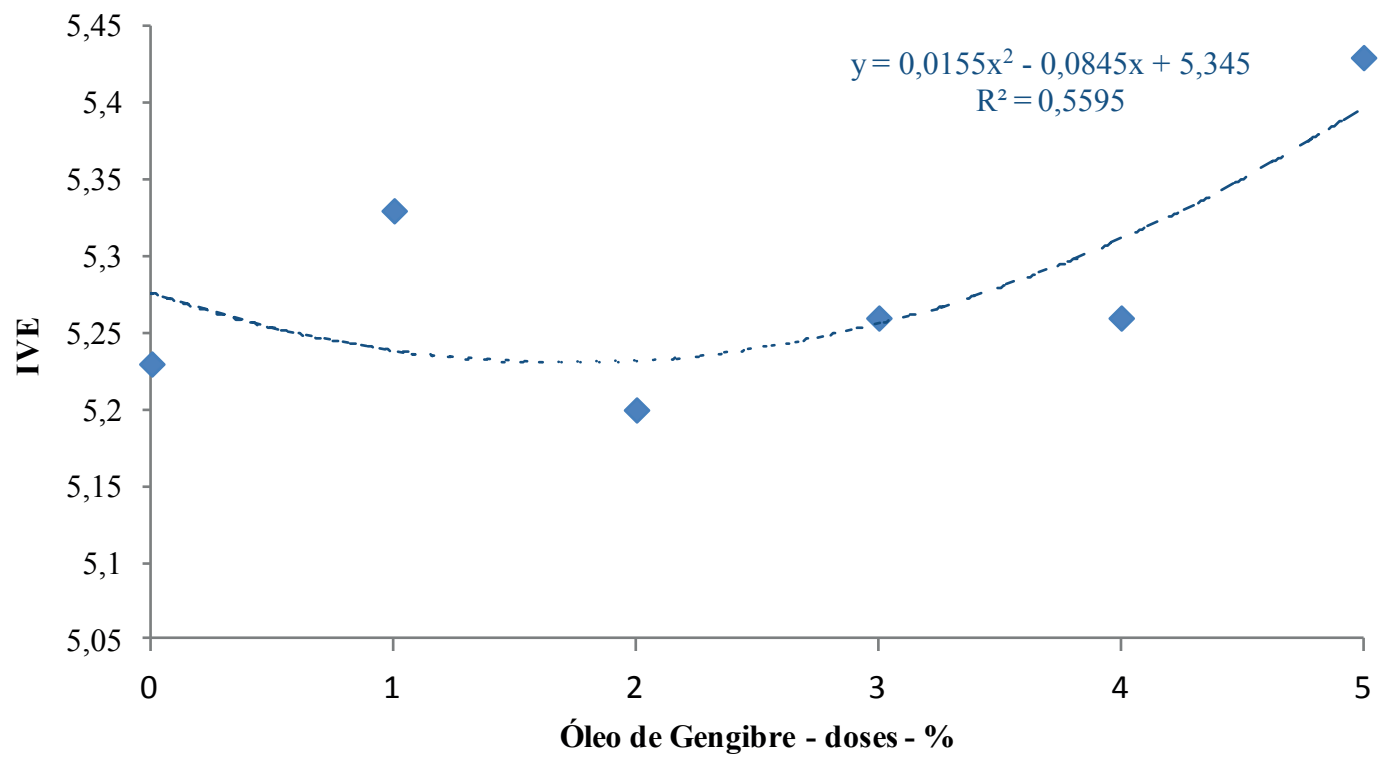

$\diamond$ Índice de Velocidade de Emergência - IVE

Figura 3. Índice de Velocidade de Emergência (IVE) das sementes de milho tratadas com óleo essencial de gengibre em diferentes concentrações (\%). UFMS - Chapadão do Sul/MS. 2016.

Baseado nos resultados do teste de sanidade, observou-se maior incidência dos fungos $F$. verticillioides na testemunha (sem óleo) (Figura 2).

Nas sementes tratadas com OE de gengibre (2\%), a incidência de fungos foi maior que nas concentrações 1, 3, 4 e 5\%. Porém, na concentração 4\%, observou-se novamente a diminuição da incidência dos fungos. Na concentração mais alta do OE de gengibre (5\%) observou-se pequeno aumento na incidência do fungo, acompanhada diretamente da queda na germinação dessas sementes (Figura 1).

O IVE permite inferir que houve efeito das concentrações utilizadas do $\mathrm{OE}$ de gengibre utilizado no tratamento das sementes de milho $(\mathrm{P}>$ $5 \%$ ). As sementes tratadas com OE de gengibre na concentração de 1\% apresentaram maior IVE em relação testemunha ( $0 \%)$ (Figura). Mas foi a maior concentração $(5 \%)$ do $\mathrm{OE}$ de gengibre que proporcionou maior velocidade de germinação das semente (Figura 3).

O tratamento de sementes é uma prática consolidada devido à sua importância na proteção contra fungos fitopatogênicos nela presentes ou não presentes na microflora do solo. Alternativamente aos produtos comerciais registrados, óleos essenciais e extratos de plantas tem sido avaliados na sua eficiência fungicida, como produtos alternativos de controle dos fungos. Os resultados obtidos neste trabalho demonstram efeito fungicida do OE de gengibre, onde foi observada a tendência de menor incidência de $F$. verticillioides, nas sementes de milho, à medida que foram utilizadas maiores doses do OE de gengibre.

A eficiência fungicida do $\mathrm{OE}$ de gengibre foi demonstrada por Gonçalves et al, (9), através de sementes de soja tratadas com OE de gengibre, na concentração de $20 \%$, onde observaram uma redução total do número de sementes infestadas com Fusarium spp. em relação à testemunha (15\%). No presente trabalho a redução do $F$. verticillioides nas sementes foi de 51,5\% na maior dose $(5 \%)$ em relação à testemunha. O mesmo não foi verificado no presente estudo, pois as concentrações utilizadas foram menores, sendo necessárias novas avaliações com concentrações maiores de óleo essencial.
$\mathrm{O}$ efeito do extrato bruto aquoso de gengibre foi avaliado por Rodrigues et al. (23) onde obtiveram resultados que comprovam a eficiência do seu uso sobre o crescimento micelial de Sclerotinia sclerotiorum (redução de 92,5\%, na concentração de $25 \%$ do extrato bruto aquoso de gengibre) e na produção de escleródios apresentando tendência linear crescente em relação às concentrações avaliadas $(1,5,10,15,20$ e 25\%). Para Santana et al. (24) o extrato bruto aquoso de gengibre (Zingiber officinale) foi eficiente no controle de Sclerotium rolfsii em plantas tomateiro apresentando redução de $52,9 \%$ da enfermidade, comparado à testemunha inoculada e não tratada (27,3\%). Assim, o uso de óleos essenciais e extratos de plantas vêm sendo intensamente pesquisados, principalmente na inibição micelial de fungos fitopatogênicos, no entanto, ainda são escassas as informações dos seus usos no tratamento de sementes de culturas importantes como milho, soja, feijão, algodão. O uso de óleos essências de plantas e de seus extratos vem demonstrando serem promissores no controle de fitopatógenos, com inúmeras dúvidas a serem ainda elucidadas, principalmente na padronização das diluições para se obter as concentrações dos óleos essenciais e extratos de plantas.

O uso de óleos essenciais em sementes de milho (Zea mays L) pode afetar o seu potencial fisiológico (porcentagem de emergência, índice de velocidade de emergência, velocidade de emergência e coeficiente de velocidade de emergência), o que foi constatado por Magalhães et al (15) ao utilizar OE de Croton heliotropiifolius Kunth, Croton pulegiodorus Baill e Ocimum basilicum L.) nas doses 0; 5; 10; 15 e 20 $\mu \mathrm{LL}^{-1}$. No presente trabalho o $\mathrm{OE}$ de gengibre proporcionou incremento no potencial fisiológico das sementes de milho, havendo aumento na emergência e no IVG, além de não afetar a germinação das sementes.

As informações mais relevantes obtidas com essa pesquisa são que o $\mathrm{OE}$ de gengibre, nas concentrações de 0 (zero), 1, 2, 3, 4 e $5 \%$, não afetaram a germinação das sementes de milho do hibrido avaliado e nas doses de 1,4 e 5\% proporcionaram menores porcentagens de incidência de $F$. verticillioides nas sementes de milho avaliadas. Dessa 
forma a oscilação na porcentagem de germinação das sementes, tratadas com diferentes concentrações do OE de gengibre foi inversamente proporcional à presença de $F$. verticillioides nas sementes. Em relação à velocidade de emergência das sementes de milho, as tratadas foram superiores quando utilizou-se a maior concentração do OE de gengibre $(5 \%)$.

\section{AGRADECIMENTOS}

Os autores agradecem à Prof ${ }^{a}$ Dra Maria das Graças Cardoso, do Departamento de Química da Universidade Federal de Lavras pela extração do óleo essencial de gengibre utilizado nessa pesquisa.

\section{REFERÊNCIAS}

1. Barnett, H.L.; Hunter, B.E. Illustrated genera of imperfect fungi. 4.ed. Saint Paul: American Phytopathology Society, 1998. 218p.

2. Bettiol, W.; Ghini, R. Proteção em sistemas agrícolas alternativos. In: Campanhola, C.; Bettiol, W. (ed.). Métodos Alternativos de Controle Fitossanitários. Jaguariúna, SP: Embrapa Meio Ambiente, 2003. 279p. Disponível em: <https://ainfo.cnptia.embrapa.br/digital/bitstream/item/164175/1/ Campanhola-Metodos.pdf $>$. Acesso em: 05 de agosto de 2017.

3. Brasil. Ministério da Agricultura, Pecuária e Abastecimento. Regras para Análise de Sementes. Brasília, DF: MAPA/ACS, 2009. 399p. Disponível $\mathrm{em}:<\mathrm{http}: / /$ www.agricultura.gov.br/assuntos/insumos-agropecuarios/arquivos-publicacoes-insumos/2946_regras_analise_sementes.pdf $>$. Acesso em: 18 de março de 2016.

4. Brasil. Ministério da Agricultura, Pecuária e Abastecimento. Manual de Análise Sanitária de Sementes. Brasília, DF: MAPA/ACS, 2009. 200 p. Disponível em: $<$ https://www.abrates.org.br/files/manual-de-analise-sanitaria-de-sementes.pdf $>$. Acesso em: 18 de março de 2016.

5. Casa, R.T.; Reis, E.M.; Zambolim, L. Doenças do milho causadas por fungos do Gênero Stenocarpella. Fitopatologia Brasileira, Brasilia/DF, v.31, p.427-439, 2006. Disponível em: <http://dx.doi.org/10.1590/S010041582006000500001>. Acesso em: 18 de outubro de 2018.

6. Casela, C.R.; Ferreira, A.S.; Pinto, N.F.J.A. Doenças na cultura do miIho. Sete Lagoas: Embrapa Milho e Sorgo, 2006. 14p. (Embrapa Milho e Sorgo Circular Técnica, 83). Disponível em: $<$ https://www.infoteca. cnptia.embrapa.br/bitstream/doc/490415/1/Circ83.pdf >. Acesso em: 18 de outubro de 2018

7. Costa, A.R.T.; Amaral, M.F Z.J.; Martins, P.M.; Paula, J.A.M.; Fiuza, T. S.; Resvenzol, L.M.F.; Paula, J.R.; Bara, M.T.F. Ação do óleo essencial de Syzygium aromaticum (L.) Merr. \& L.M. Perry sobre as hifas de alguns fungos fitopatogênicos. Revista Brasileira de Plantas Medicinais, Botucatu, v.13, n.2, p.240-245, 2011. Disponível em: $<$ http://dx.doi.org/10.1590/ S1516-05722011000200018>. Acesso em: 30 de setembro de 2016.

8. Ferreira, D.F. Sisvar: a computer statistical analysis system. Ciência e Agrotecnologia, Lavras, v.35, n.6, p.1039-1042, 2011. Disponível em: $<$ http://dx.doi.org/10.1590/S1413-70542011000600001>. Acesso em: 30 de julho de 2016.

9. Gonçalves, G. G.; Mattos, L. P. V.; Morais, L. A. S. Óleos essenciais e extratos vegetais no controle de fitopatógenos de grãos de soja. Horticultura Brasileira, Vitoria da Conquista, v.27, n.2, p.102-107, ago. 2009. Disponível em: <https://ainfo.cnptia.embrapa.br/digital/bitstream/ item/143459/1/2009AA-053.pdf $>$. Acesso em: 05 de março de 2016.

10. Goulart, A.C.P. Deteç̧ão e controle químico de Colletotrichum em sementes de soja e algodão. Dourados: Embrapa Agropecuária Oeste, 33p. (Documento, 100). 2009. Disponível em: <https://www.infoteca.cnptia. embrapa.br/bitstream/doc/574033/1/DOC2009100.pdf $>$. Acesso em: 20 de fevereiro de 2016.

11. Kuhnem Júnior, P. R.; Stumpf, R.; Spolti, P.; Del Ponte, E. M. Características patogênicas de isolados do complexo Fusarium graminearum e de Fusarium verticillioides em sementes e plântulas de milho. Ciência Rural, Santa Maria, v.43, n.4, p.583-588, 2013. Disponível em: <http://www.scielo.br/ pdf/cr/v43n4/a11113cr2012-0864.pdf> Acesso em: 13 de março de 2016.

12. Limonard, T. A modified blotter test for seed health. Netherland Journal of Plant Pathology, Wageningen, v.72, p.319-321, 1966.

13. Machado, J.C. Salt agar medium to detect storage fungi in seed. Method 17. In: Machado, J.C.; Langerak, C.J.; Jaccoud-Filho, D.S. Seed-Borne Fungi: A contribuition to routine seed health analysis. 1st. ed. Bassersdorf, ISTA, 2002.138p.

14. Machado, J.C. Tratamento de Sementes no controle de doenças. Lavras: Editora UFLA, 2000. 134p.

15. Magalhães, C.R.I.; Brito, S.S.S.; Magalhães, T.A.; Ferraz, M.S.S.; Oliveira, C.R.F. Óleos essenciais na emergência de grãos de milho (Zea mays L.). Enciclopédia Biosfera, Goiânia, v.10, n.19, p.338-349. 2014. Disponível em: <http://www.conhecer.org.br/enciclop/2014b/AGRARIAS/oleos\%20 essenciais\%20na\%20emergencia.pdf $>$. Acesso em: 03 de dezembro de 2016.

16. Maguire, J.D. Speed of germination-aid in selection and evaluation for seedling emergence and vigor. Crop Science, Madison, v.2, n.2, p.176-177, Mar./Apr. 1962. Disponível em: $<$ http://www.scielo.br/scielo.php?script=sci_nlinks\&ref=000093\&pid=S1413-7054200800020001500014\&lng=pt>. Acesso em: 03 de dezembro de 2016

17. Martins, J.A.S.; Sagata, É.; Santos, V.A.; Juliatti, F.C. Avaliação do efeito do óleo de Melaleuca alternifolia sobre o crescimento micelial in vitro de fungos fitopatogênicos. Bioscience Journal, Uberlândia, v.27, n.1, p.49-51, 2010. Disponível em: $<$ http://www.seer.ufu.br/index.php/biosciencejournal/ article/view/7379>. Acesso em: 03 de dezembro de 2016.

18. Nash, S.M.; Snyder, W.C. Dissemination of the root rot Fusarium with bean seed. Phytopathology, St. Paul, v.54, p.880, 1964.

19. Milho. Acompanhamento da Safra Brasileira: grãos, Brasília, DF, v.4, n.6, p.106-117, Março/2017. Safra 2016/17, sexto levantamento. Brasília, 2017. Disponível em: <https://www.conab.gov.br/info-agro/safras/graos/ boletim-da-safra-de-graos?start=30>. Acesso em: 19 de març, 2016.

20. NEE;AARD, P. Seed Pathology. London: MacMillan Press, 1191p. 1977.

21. Oliveira, J.B.; Biondo, V.; Schwan-Estrada, K.R.F. Extratos e tinturas vegetais sobre o cerscimento micelial de Corynespora cassiicola e indução de fitoalexinas em soja. Revista UNINGÁ Review, Maringá, v.17, n.3, p.5-10, 2014.

22. Rey, M.S., Lima, N.B.; Santos, J.; Pierobom, C.R. Transmissão semente-plântula de Colletotrichum lindemunthianum em feijão (Phaseolus vulgaris). Arquivos do Instituto Biológico, São Paulo, v.76, n.3, p.465470, jul./set. 2009.

23. Rodrigues, E.; Schwan-Estrada, K.R.F.; Fiori-Tutida, A.C.G.; Stangarlin, J.R.; Cruz, M.E.S. Fungitoxicidade, atividade elicitora de fitoalexinas e proteção de alface em sistema de cultivo orgânico contra Sclerotinia sclerotiorum pelo extrato de gengibre. Summa Phytopathologica, Botucatu, v.33, n.2, p.124-128, 2007. Disponível em: < http://www.scielo.br/pdf/sp/ v33n2/a04v33n2.pdf>. Acesso em: 04 de setembro de 2016.

24. Santana, K.F.A.; Dezordi, C.; Coelho Netto, R. A.; Hanada, R. E. Avaliação do controle da podridão de Sclerotium rolfisii, em tomateiro (Solanum lycopersicum), por meio do uso de extratos de planta. In: Jornada de Iniciação Científica PIBIC CNPq/FAPEAM/INPA, 18., Manaus, 2009. Anais. Cidade: Editora, 2009. p.67-70.

25. Sartori, A. F.; Reis, E. M.; Casa, R. T. Quantificação da transmissão de Fusarium moniliforme de sementes para plântulas de milho. Fitopatologia Brasileira, Brasília, DF, v.29, n.4, p.456-458, jul./ago. 2004. DOI: 10.1590/ S0100-41582004000400018.

26. Schwan-Estrada, K.R.F. Extratos vegetais e de cogumelos no controle de doenças de plantas. Horticultura Brasileira v.27, n.2, p.S4038-S4045, 2009. Disponível em: <http://www.abhorticultura.com.br/eventosx/trabalhos/ev_3/MR_4_Artigo_Katia_Regina_Estrada.pdf>. Acesso em: 24 de março de 2016 .

27. Teixeira, H.; Machado, J.C. Transmissibilidade e efeito de Acremonium strictum em sementes de milho. Ciência e Agrotecnologia, Lavras, v.25, n.5, p. 1045-1052, set/out. 2003. 